\title{
Realistic beach slope prediction and design
}

\author{
K.D. Seddon ATC Williams Pty Ltd, Australia \\ T.G. Fitton ATC Williams Pty Ltd, Australia
}

\begin{abstract}
This paper discusses the issue of the true reliability of a beach slope prediction method. Beach profiles have been predicted for five sites where there is reasonable information available regarding the operating variables that influence slope. Data derived from operating records show significant variability in two of the main controlling parameters: throughput (flow rate) and solids concentration (rheology or flow resistance).

A combination of these variables has been used to calculate predicted beach slopes over the top, middle and lower thirds of the tailings beaches studied. Reasonable agreement between predicted and observed profiles has been obtained for both the overall slopes, and the measured slope concavity.
\end{abstract}

The use of this approach to address beach concavity at the design stage is discussed.

\section{Introduction}

One of the central concepts of the thickened discharge system is that discharge of thickened tailings will result in a consistent beach slope (Robinsky, 1999). The implication is that for a constant flow rate and slurry density (or strictly, for constant slurry rheology), tailings will form a uniform planar beach slope down the full length of the beach. In practice, tailings properties and discharge rates do not stay constant, and beach profiles with some degree of concavity are commonly encountered.

However, the design of a beach slope for a greenfields site entails much more than just calculating a slope. It firstly involves assessment and selection of realistic input parameters, or more correctly, a realistic range of input parameters. Once these are determined, and only then, a reliable method of beach slope prediction is required.

The problem with parameter selection derives from the fact that conditions of constant discharge and rheology are not perfectly realised, and in some cases these factors are deliberately modified during the life of a facility. In many instances process rates will be increased with time due to plant upgrades, both incremental and major. The type or mix of ore may also vary during the mine life, with impacts on the resulting slurry rheology. Conscious decisions regarding the operation of thickeners may be implemented (for example, Murphy, 2006) resulting in a step change in solids concentration and slurry rheology. Finally, site operations and depositional methods can have a significant influence on local flow rates, and hence beach slope.

Even in cases where relatively stable operations are achieved over an extended period, there will be unavoidable variations in flow rate and rheology, and the result of these variations must be taken into consideration in the design.

The relatively poor correlation of beach slopes achieved in practice compared to initial design values has been noted (Jewell, 2010). In some cases this may indeed be the direct result of inadequate slope forecasting methods. However, it is likely that there are at least as many cases where the poor correlation is due to the discrepancy between fundamental design assumptions used as inputs to beach slope models, and the conditions that actually apply during operations.

The purposes of this paper are therefore to firstly consider the variability of data that influence beach slope. Secondly, it is to look at the reliability of beach slope prediction, based not on initial design assumptions (which may be incorrect), but rather on the actual variables that apply to the measured beach slope. Finally, it is to discuss how this may be rationally applied at the design stage. 


\section{Background}

The issue of methods of beach slope prediction was highlighted ten years ago, when Williams (2001) noted that (at that time) there was no known theoretical basis for predicting the slope of a thickened tailings stack at the design stage. Given the key importance of the beach slope for the design of stacked tailings schemes, research into the problem was clearly needed. An approach was proposed based on the geomorphology of beach formation, and the requirement for methods to analyse the hydraulics of flow in the self-formed channels that are typically observed when tailings slurries are discharged sub-aerially onto a beach.

The ensuing decade has indeed seen wider recognition of the issue and a significant increase in the attention being paid to it. Improved slope prediction methods based on the "channel geomorphology" approach have been developed (Pirouz and Williams, 2007; Fitton et al., 2007).

During this period it was also recognised that in practice slurry rheology and flow rate are never truly uniform, due to variability in thickener performance, ore characteristics, grind size, etc. Thickened tailings will therefore deposit to form a concave beach profile. This should not be confused with the much more pronounced concavity that results from segregating tailings deposition. Fitton et al. (2007) showed that for one case (Sunrise Dam) the observed concave beach slopes profiles could be adequately modelled by explicitly varying the relevant parameters (flow and rheology) in a stepwise daily deposition model. This was a significant result, as it indicated how this variability could be a predicted in advance in a design case, with the parameters verified by back analysis of historical data.

A second review paper (Williams et al., 2008) noted these developments and also presented a tabulation of known thickened tailings schemes to date.

\section{Methodology}

To check on the reliability of a beach slope prediction method data sets have been obtained from sites where survey (or air photo records) of actual beach slopes are available at a known time, plus records of the relevant input parameters over a significant period preceding the time of survey.

Data have been obtained from the following sites:

- Century (Queensland)

- Ernest Henry (Queensland)

- Miduk (Iran)

- Peak (NSW)

- Sunrise Dam (Western Australia).

The thickened tailings facilities at these sites were designed by ATC Williams, and most of the data are available due to involvement in studies or management and surveillance of these facilities.

The minimum required data are slope profile, indicative flow rate and solids concentration, plus a contemporary determination of rheology. There are some gaps in the records used, and these are discussed in the individual cases below. In the majority of the cases more complete sets of operating data including continuous records of throughput and slurry density have been obtained, and this is certainly the optimum situation. Whilst daily data has been the preferred sample interval, in some cases only monthly data are available.

Some of the records cover a period of years (up to the whole mine life), but for the purposes of this study periods where major changes in parameters are evident have been explicitly excluded. This includes both stepwise changes in slurry density (mostly increases), and increments in overall throughput. The aim has been to select periods of at least one year of consistent operation prior to the beach survey.

The selected data sets have been analysed for parameter variability, as discussed in Section 4. A check on autocorrelation between solids concentration and throughput was carried out. No significant correlation was found, and for the purposes of analysis these parameters have been taken to be independent. 
All of the beaches studied (Section 5) exhibit concavity, and for the purpose of this paper this has been simplified by drawing longitudinal sections of the beach profile, which has then been sub-divided into thirds (with respect to horizontal distance along the beach), with representative slopes adopted for each section.

Individual beach slope lengths vary considerably, from a minimum of about $300 \mathrm{~m}$ to a maximum of $3,000 \mathrm{~m}$. To assist comparison, normalised profiles have been adopted (ie elevation and distance down the slope have both been divided by total slope length).

It is not the intent of this paper to undertake a comparison of individual beach slope prediction methods. Consequently all beach slope calculations in this paper have been carried out using just one method: the "Fitton Non-segregating" method (Fitton et al., 2007). This method calculates a minimum non-settling velocity for a non-segregating slurry, based on tailings characteristics, and then calculates the beach slope that is required to enable this minimum velocity to be achieved in a self formed channel, again for the particular slurry and flow characteristics. This slope is the equilibrium or design slope.

The calculation of beach concavity has been undertaken by a combination of the controlling variables as summarised in Table 1, recognising that for a normal distribution a value of Mean $+/-1$ SD is $84 \%$ and $16 \%$ respectively of the cumulative distribution. These values are therefore notionally representative of the parameters applying to the upper and lower thirds of a beach profile.

The application of parameter variability shown in Table 1 is due to the fact that beach slope is proportional to slurry concentration (rheological parameters and flow resistance), whilst it is inversely proportional to flow rate. Steeper beach slopes therefore occur for lower flows, and higher slurry densities.

Table 1 Calculation of concavity

\begin{tabular}{lll}
\hline & Discharge Rate & Slurry Concentration \\
\hline Upper third & Mean $-(1 \times \mathrm{SD})$ & Mean $+(1 \times \mathrm{SD})$ \\
Central & Mean & Mean \\
Lower third & Mean $+(1 \times \mathrm{SD})$ & Mean $-(1 \times \mathrm{SD})$ \\
\hline
\end{tabular}

Values of the actual magnitude of standard deviation that may be appropriate for use in design are discussed in terms of the coefficient of variation (standard deviation/mean). For the purposes of this paper the same coefficient of variation has been used for all sites, as discussed in Section 4.

It is also recognised that the allocation of parameter variation to locations on the beach as per Table 1 is a simplification. Consideration of the mass of tailings that report to different sections of a beach profile would suggest that the overall shape of the beach (i.e. whether down valley or CTD) should be taken into account. The values given in Table 1 are probably most applicable to down valley discharge to a storage having a reasonably uniform cross section. Different assumptions regarding parameter distribution may be more appropriate for cases where more mass is deposited on the lower slopes (e.g. down valley discharge where the width of the valley increases significantly, through to CTD cases). This additional modification has not been attempted in this paper.

\section{$4 \quad$ Variability of inputs}

\subsection{Solids concentration}

Cumulative distribution curves for slurry concentration are shown in Figure 1 for four sites. The distributions approximate normal distributions. Additional details are summarised in Table 2 including values for mean, standard deviation and coefficient of variation.

The results indicate significantly lower variability at Sunrise dam and Miduk compared to the other two sites. However, it should be noted that the duration of record analysed at the other sites is greater. Note that the data for Century are mean monthly figures, and should be expected to exhibit significantly lower variability. The data for Miduk are for the combined outflow of four separate thickeners. As would be expected, the coefficient of variation of this distribution (0.02) is lower than that of the individual thickeners. 
It should also be noted that at Miduk the discharged tailings flow down a natural valley to the storage area. Some extraneous water inflows dilute the tailings prior to discharge. An estimate correction has been applied (Figure 1) to the thickener underflow concentration to calculate the actual beach slope.

\section{Tailings Density: Cumulative Distributions}

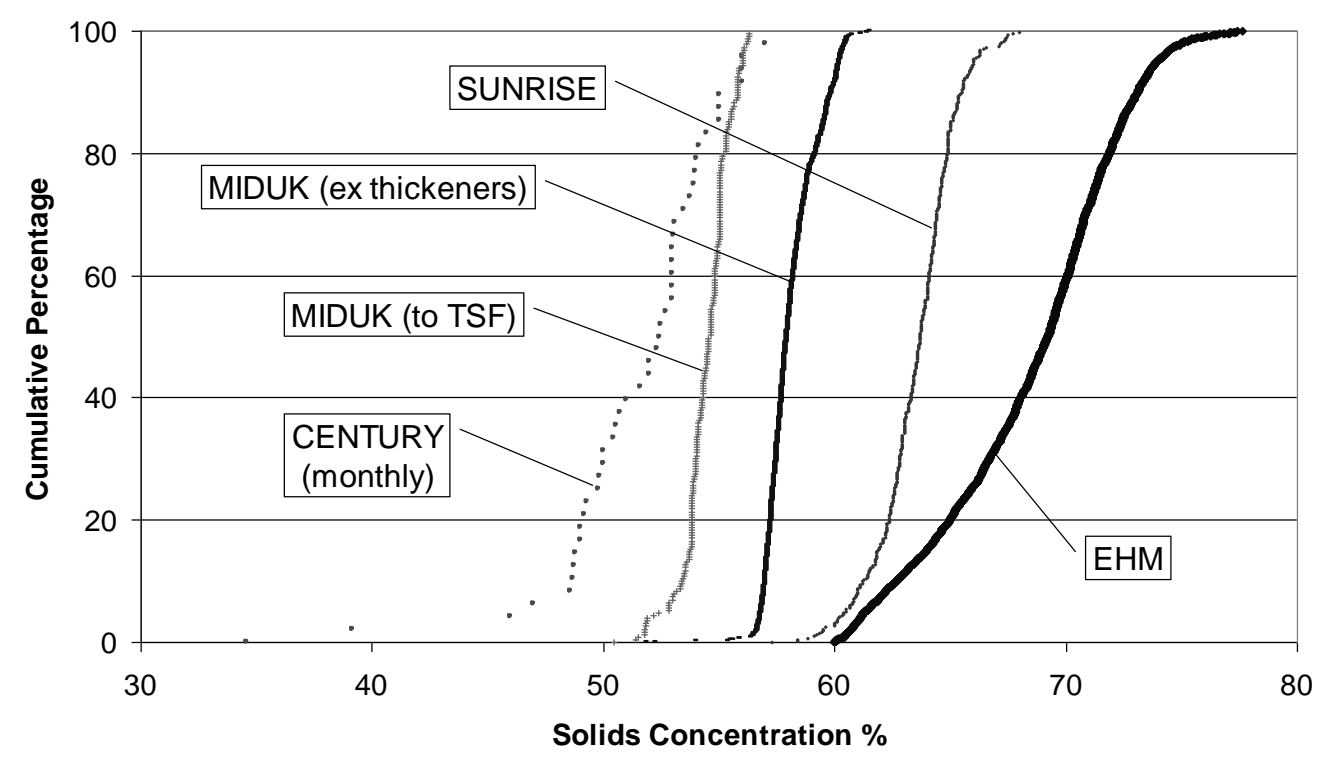

Figure 1 Variability in feed density: cumulative distributions

For the purposes of this paper, a coefficient of variation of 0.05 has been applied to the solids concentration in all cases.

Finally, to calculate beach slope using the Fitton non-segregating method, it is necessary to obtain representative rheological parameters for the adopted tailings concentration. It is well established that rheological strength is non-linear with respect to solids concentration, and consequently the applicable rheological parameters can be expected to exhibit considerably more variation than the solids concentration. For each of the sites studied, a set of rheograms was available from laboratory testing at a range of concentrations. For each concentration a design value for rheological parameters was obtained by interpolation from the test data set.

Table 2 Variability of slurry density (solids concentration)

\begin{tabular}{lllll}
\hline Site & EHM & Century & Sunrise & $\begin{array}{l}\text { Miduk } \\
\text { (4 Thickeners) }\end{array}$ \\
\hline Period analysed & $01 / 00$ to $10 / 10$ & $10 / 06$ to $10 / 10$ & $11 / 03$ to $12 / 04$ & $08 / 09$ to 04/10 \\
Sample rate & 12 hours & Mean monthly & 24 hours & 24 hrs \\
Mean & 68.5 & 51.4 & 63.5 & 57.8 to 58.6 \\
SD & 3.8 & 4.0 & 1.7 & 1.17 to 1.48 \\
Coeff. var. & 0.056 & 0.078 & 0.026 & 0.020 to 0.026 \\
\hline
\end{tabular}

\subsection{Tonnage/flow rate}

The Fitton beach slope model utilises instantaneous flow as an input. Actual data on short term flow variations are difficult to acquire: generally the best that is available is daily tonnage, or occasionally twice daily. These values have been used for this study without further factoring for variation throughout the day. 
Cumulative distribution curves for production tonnages for four sites are shown in Figure 2, with additional details summarised in Table 3. The distributions approximate normal distributions, but with slightly skewed tails at the low flow side. Theoretical (statistically correct) values for mean, standard deviation and coefficient of variation are shown in Table 2 . It is possible that slightly adjusted values would give an overall better fit to the curves, or alternatively a distribution that explicitly includes skewness could be used in preference to a normal distribution. This has not been attempted in this paper.

It should be noted that for the case of Ernest Henry only monthly data are available, and the lower variability of this site compared to daily data is to be expected.

\section{Feed Tonnage: Cumulative Distribution}

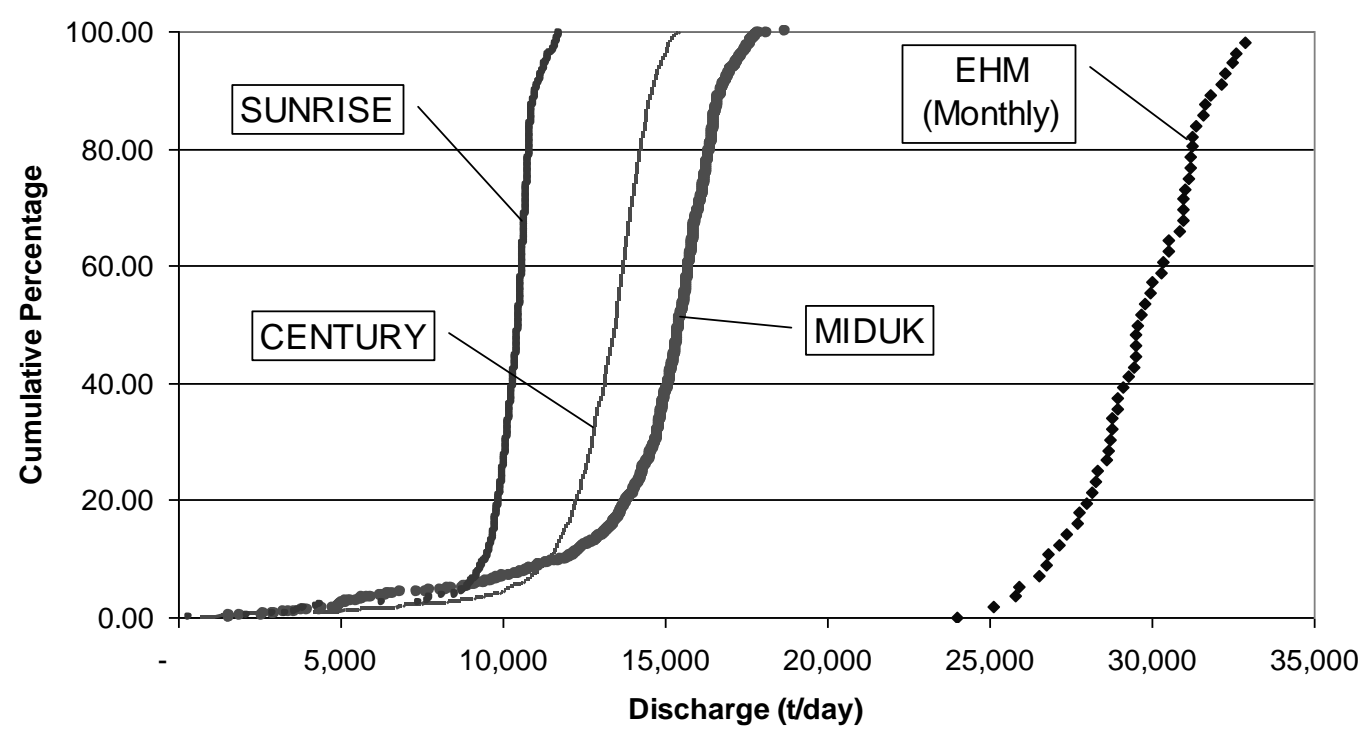

Figure 2 Variability in feed rate: cumulative distributions

For the beach slope calculations carried out for this study a coefficient of variation of 0.10 (ie $+/-10 \%$ of mean) has been used in all cases. This is less than each of the three values obtained from the daily data sets shown in Table 3. It is possible that a value closer to 0.15 would be more appropriate.

\section{Table 3 Summary of feed variability}

\begin{tabular}{lllll}
\hline Site & EHM & Century & Sunrise & Miduk \\
\hline Period analysed & $06 / 04$ to 01/09 & $10 / 06$ to 06/10 & $11 / 03$ to 12/04 & $06 / 07$ to 04/10 \\
Sample rate & Mean monthly & 24 hours & 24 hours & 24 hours \\
Mean & 29,500 & 13,060 & 10,240 & 14,700 \\
SD & 1,990 & 1,830 & 1,200 & 2,760 \\
Coeff. var. & 0.07 & 0.14 & 0.12 & 0.19 \\
\hline
\end{tabular}

\section{$5 \quad$ Beach slope predictions}

\subsection{Adopted input parameters}

The input data used for each case have been prepared in accordance with the methodology discussed previously, and are summarised in Table 4. 


\section{Table 4 Beach slope prediction input data}

\begin{tabular}{lcccccc}
\hline & & & & \multicolumn{3}{c}{ Rheology } \\
Site & Slope & Through- & Solids & & & \\
& Segment & $\begin{array}{c}\text { put } \\
\text { (ponc. }\end{array}$ & to & K & n \\
& & \% w/w & (Pa) & $($ Pa.s^n) & \\
\hline Century & Upper & 4.59 & 56.7 & 15.0 & 0.029 & 1.0 \\
(Queensland) & Middle & 5.10 & 54.0 & 10.0 & 0.023 & 1.0 \\
& Lower & 5.61 & 51.3 & 6.0 & 0.014 & 1.0 \\
\hline Ernest Henry & Upper & 7.74 & 73.5 & 1.7 & 1.417 & 0.5 \\
(Queensland) & Middle & 8.60 & 70.0 & 0.0 & 0.350 & 0.6 \\
& Lower & 9.46 & 66.5 & 0.0 & 0.250 & 0.6 \\
\hline Miduk & Upper & 4.37 & 57.8 & 18.0 & 2.525 & 0.4 \\
(Iran) & Middle & 4.85 & 55.0 & 10.5 & 1.910 & 0.4 \\
& Lower & 5.34 & 52.3 & 5.8 & 0.495 & 0.4 \\
\hline Peak & Upper & 0.50 & 55.7 & 2.5 & 0.056 & 0.8 \\
(NSW) & Middle & 0.55 & 53.0 & 1.6 & 0.037 & 0.8 \\
& Lower & 0.61 & 50.4 & 1.0 & 0.030 & 0.8 \\
\hline Sunrise Dam & Upper & 3.24 & 63.0 & 11.0 & 0.259 & 0.6 \\
(Western & Middle & 3.60 & 60.0 & 6.1 & 0.169 & 0.6 \\
Australia) & Lower & 3.96 & 57.0 & 3.6 & 0.120 & 0.6 \\
\hline & & & & & & \\
\hline
\end{tabular}

\subsection{Century}

The Century thickened tailings facility is a down-valley discharge. It has a high rate thickener, and has been operating for over 10 years.

Due to operational changes, there were progressive increases in both throughput and solids concentration up to 2006 (Murphy, 2006). Operational data are reasonably constant thereafter, and the analysis is based on data from October 2006 onwards. Only mean monthly figures are available for solids concentration. There is no recent rheology available for this site, and the calculations have been based on testing by ATC Williams in 2004.

The beach slope profile has been obtained from the most recent surveillance (October 2010). 


\section{Normalised Beach Profiles: Measured v predicted}

CENTURY

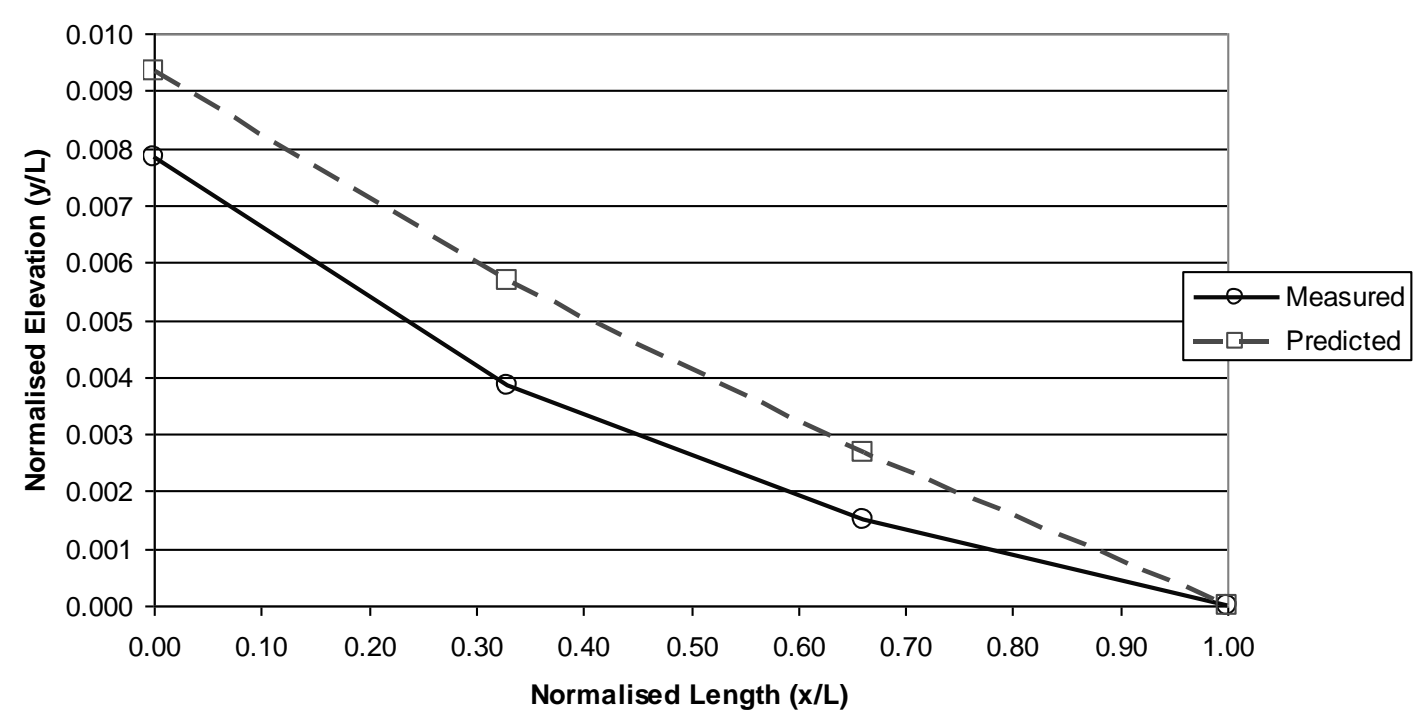

Figure 3 Century beach slope profile

A comparison of the measured and predicted profiles is shown in Figure 3. There is good agreement for upper and middle sections of the beach. The toe is flatter than predicted, suggesting that greater design variability may be required.

\subsection{Ernest Henry}

This facility was designed as a single point discharge (to a quadrant, not a full circle). Further details are provided in Amiconi and Seddon (1999). In later years modified operating procedures were instituted which make meaningful slope prediction more problematic. Consequently the beach slope predictions are based on a 2001 survey.

The facility has an Eimco High Density thickener. Data on solids concentration are available for a full 10 years period, and show that a wide range of solids concentrations in the range 60-75\% has been achieved. It is possible that some of this variation is due to variations in SG of the ore. Only monthly average data is available for production throughput.

In this case contemporary rheological data are not available, and predictions have been based on 1994 rheological parameters obtained during design. This reduces the value of this data set.

The results are shown in Figure 4. The prediction underestimates slope, across all beach segments. This suggests that either the rheology is incorrect (which is possible given the date of the test work) or there is a shortcoming in the method of analysis. In this regard it is possible that the calculation of the minimum transport velocity employed in the Fitton non-segregating model, which was calibrated against flows having a SG around 2.8, does not adequately extrapolate to the higher SG values which apply at this site. 
Normalised Beach Profiles: Measured v predicted

ERNEST HENRY

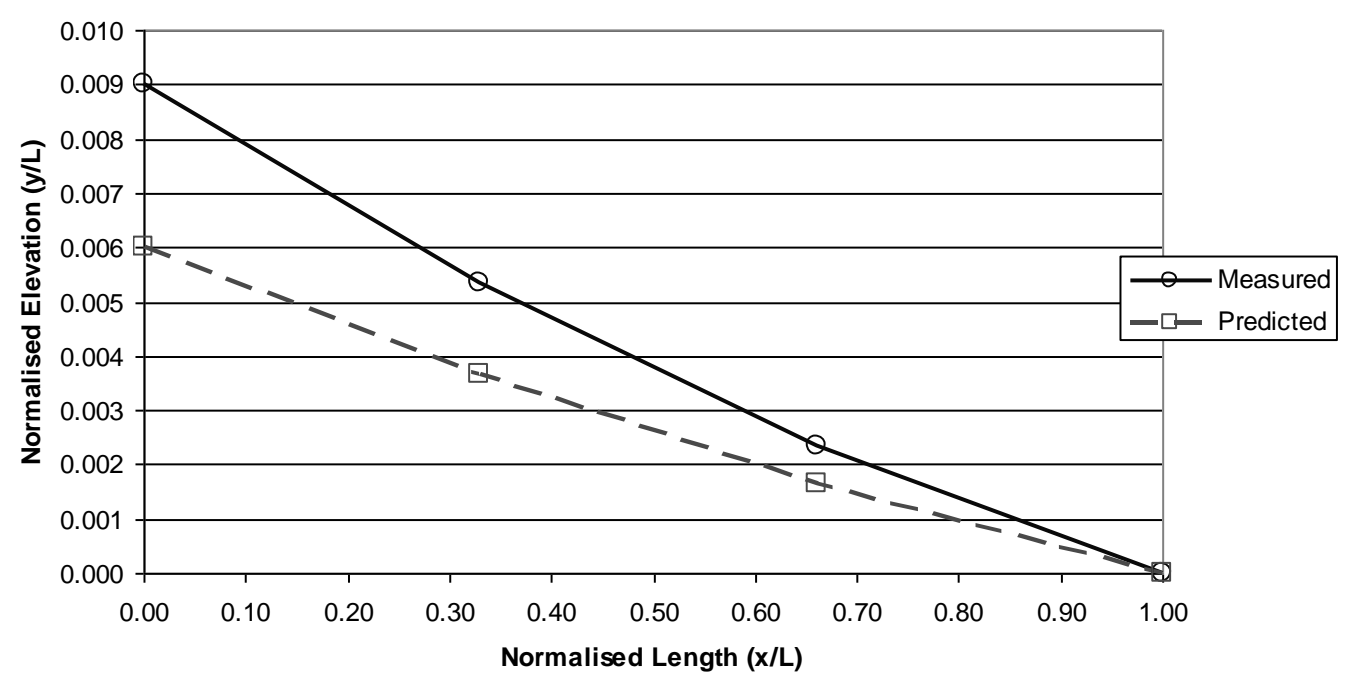

Figure 4 Ernest Henry beach slope profile

\subsection{Miduk}

Miduk is a down valley site with a single point discharge (Williams et al., 2006). The operation commenced production in 2004 and ramped up to current levels by the start of 2008.

Miduk has four Eimco (FLSmidth) paste thickeners installed, operating at an average slurry concentration of about 58\% solids, which is still well below the design value. There is quite low variability in solids concentration from individual thickeners, and even less when the combined output is considered. Because of dilution downstream of the discharge point calculated solids contents at the head of the beach for the period from August 2009 onwards have been used for the calculation.

The overall throughput rate has been reasonably consistent since 2008, but the cumulative distribution curve (Figure 2) shows a long (lower tonnage) tail in comparison to other sites.

The slope predictions have been based on rheological parameters measured in August 2010. The beach slope profile was obtained from a May 2010 survey.

The results of the prediction are shown in Figure 5 and generally significantly under-predict the achieved slopes. There are two possible reasons for this discrepancy. The first relates to the shape of the storage, in that the upper section of the actual beach is relatively narrow, and the material deposited in this area and contributing to the slope is significantly less than the one third implicit in the slope calculation. However this alone is not considered to be sufficient cause for the discrepancy. It is be more likely that the calculation of dilution downstream of the thickener is an overestimate, and that higher rheology values should be used in the calculation.

It is noted here that Jewell (2010), based on data presented in Williams et al. (2008), suggested that the fact that the measured slopes at Miduk had not yet attained the design slope indicated a deficiency in the original beach slope prediction methodology. The discussion above indicates that the Miduk case is more complicated than a simple failure in prediction, and highlights the importance of assessments based on maximum knowledge of a site. 


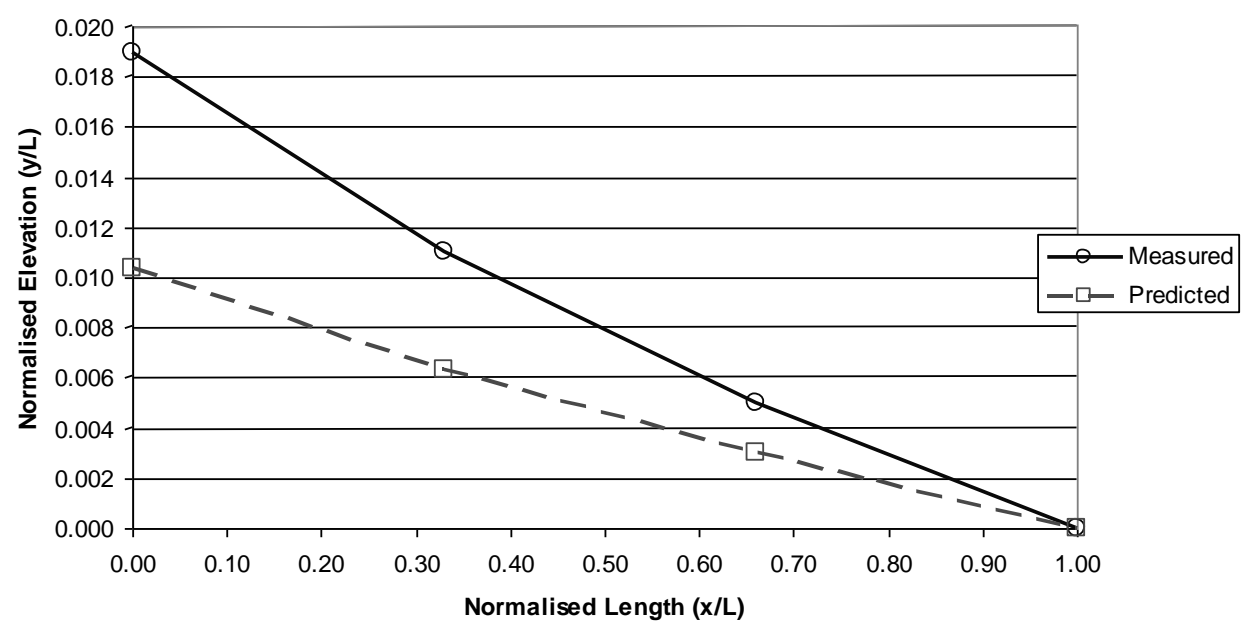

Figure 5 Miduk beach slope profile

\subsection{Peak}

The Peak facility is a CTD stack. It has a high rate thickener. Recent data are not available for this site, and the prediction has been based on older records. Only mean throughput and slurry density data are available, and therefore it is not possible to compare the adopted variability with actual values.

Beach slope data was taken from a 2001 survey. At that time tailings discharge was being split into three separate streams onto the stack to increase the beach slope, and this has been allowed for in the calculations. The rheological data date from 2004.

\section{Normalised Beach Profiles: Measured v predicted PEAK}

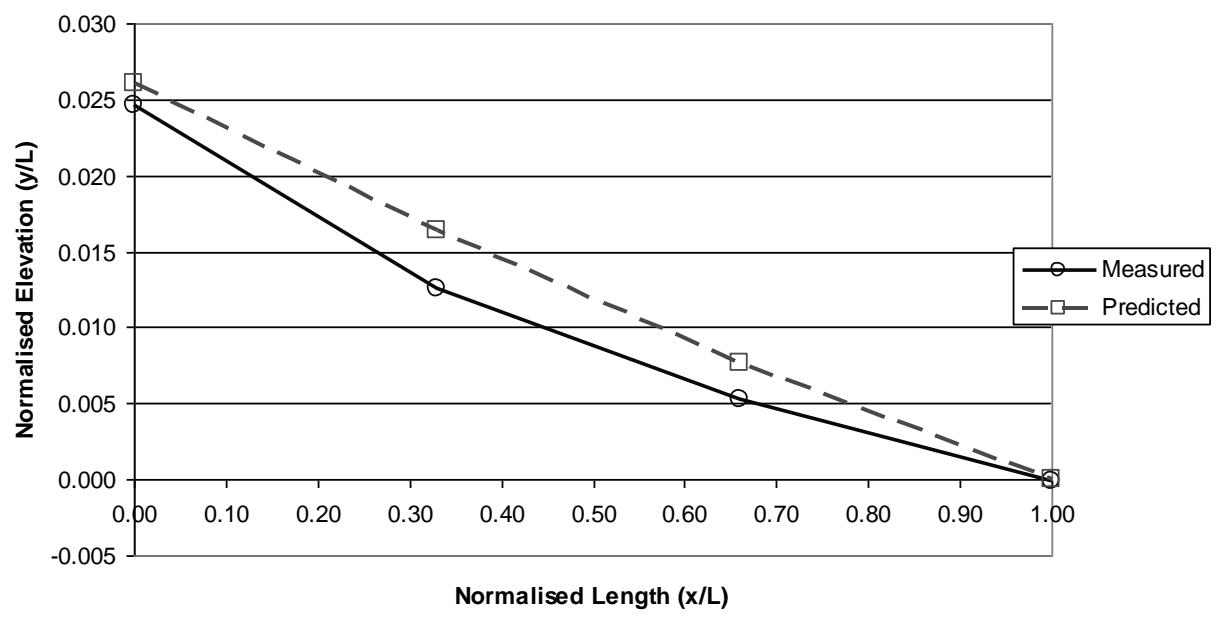

\section{Figure 6 Peak beach slope profile}

The results are summarised in Figure 6, and show very good overall agreement. The greater measured curvature suggests slightly more site variation in throughput and rheology than the values used in the analysis.

Peak was one of the sites where flume testing and data collection was carried out that was subsequently used in development of the prediction method used. Reasonable correlation should therefore be expected. 


\subsection{Sunrise Dam}

Like Peak, Sunrise Dam is a CTD stack, with a high rate thickener, and research testwork and data collected from this site were used in the development of the prediction method.

The facility has been operating since 2001, and the thickener underflow solids concentration has progressively increased with time, starting at around $60 \%$ and increasing up to $64 \%$ solids. It is noted that Sunrise dam operates with hyper-saline water, and unless a specific correction is made, this inflates the calculated solids content. The values given in this paper are uncorrected.

Distribution analyses for both density and discharge rate (Figures 1 and 2) are based on 2004 daily data. The results show comparatively tight control of both rate and density in comparison to other sites.

Normalised Beach Profiles: Measured v predicted

SUNRISE

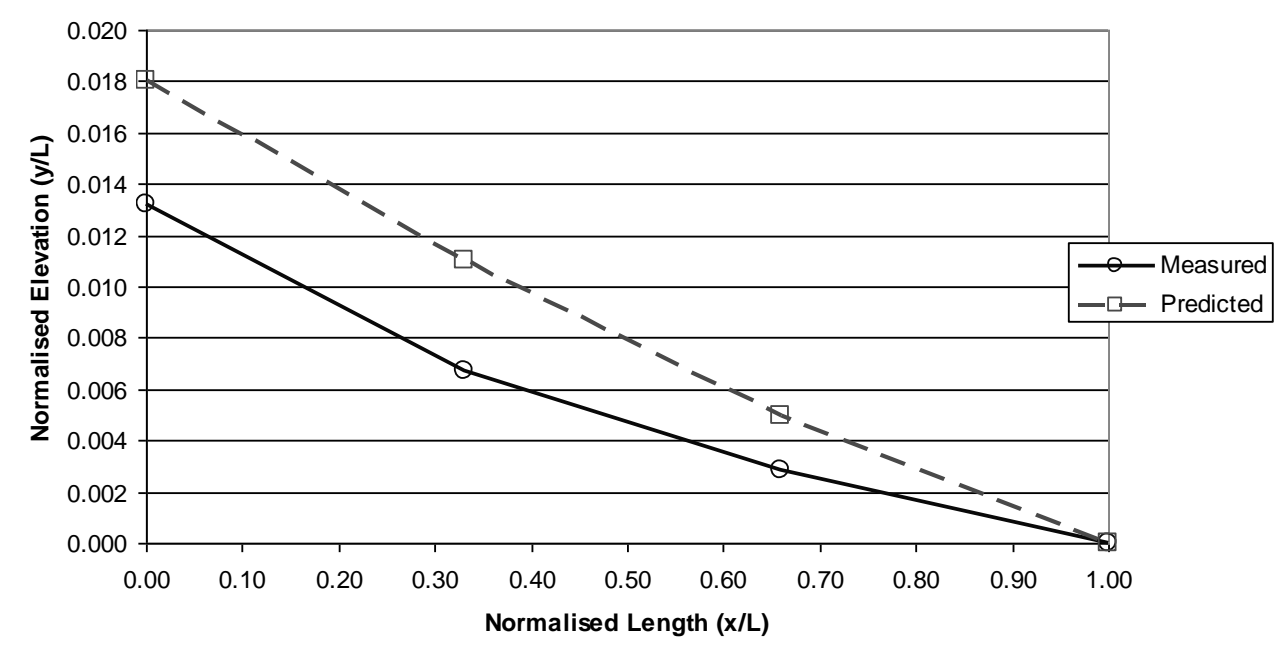

Figure 7 Sunrise Dam beach slope profile

Beach slope data have been taken from a 2004 survey. At this time discharge was being split into three separate streams at the top of the stack to increase the beach slope, and this is allowed for in the calculations.

Rheological data for this site are available from 2005 testwork.

The results are summarised in Figure 7. They show good agreement for the upper part of the slope, and a slight overestimate for the middle and lower slopes. The greater measured curvature suggests slightly more site variation than the distribution data may indicate.

\section{Discussion}

\subsection{Reliability of prediction}

The overall slope predictions obtained are summarised in Figure 8. In three out of the five cases reasonable predictions of slope have been achieved. The exceptions are Miduk (where flow dilution is a possible factor), and Ernest Henry (where old rheological data were used, or the high particle SG may be a contributing factor).

The method used goes some way towards recovering the observed beach concavity, but in most cases this is still under-predicted.

There are a number of possible reasons for this under-prediction. The method used in this paper adopted a variation of $10 \%$ for throughput, based on daily data. The actual values given in Table 3 suggest that this is an under-estimate. In addition, there may need to be a further correction to allow for the variability of instantaneous flow throughout any given day. 
Inclusion of an allowance for slurry dilution after discharge from the thickener may also be necessary in some cases.

Finally, the applicability of the adopted distribution (ie +/- 1 SD) for each of the "thirds" of a beach (Table 1) could be further considered with respect to the overall shape of the actual beach.

Fitton Non-Segregating Beach Slope Model - Fit Plot

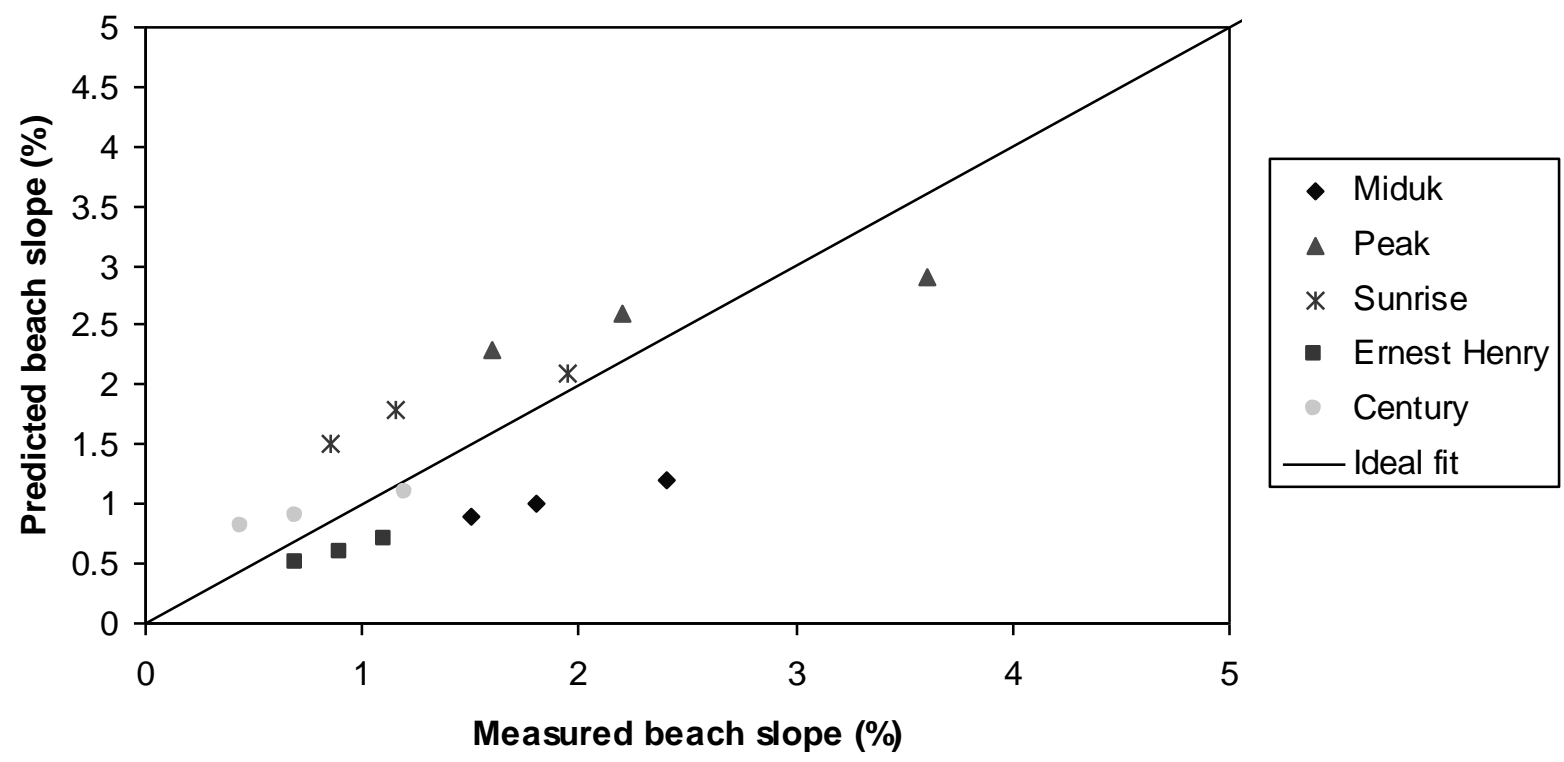

Figure 8 Summary of slope predictions

\subsection{Design procedure}

\subsubsection{Overview}

The method of analysis used in this paper lends itself to the design (forward prediction) of beach slope concavity.

The basic steps in the process are:

- Establish statistical distributions (cumulative curves) for the key parameters of throughput and solids concentration.

- Give consideration to the shape of the storage and beach, and adjust the proportions of the cumulative distributions contributing to each section of beach if considered appropriate.

- Convert solids concentration to equivalent slurry rheology.

- Make allowance for other relevant factors such as number of planned discharge points, dilution of flow, etc.

- Select an appropriate method (or methods) of beach slope prediction, and calculate the beach profile.

It terms of overall use in design, it is considered that the beach profile technique used in this paper will be most applicable in the case of preliminary studies, where a reasonably rapid approximation of a beach profile is required. For detailed design the method can be relatively easily extended to a full stochastic simulation in which the statistical distributions are used to generate a beach slope (on a daily basis), and a beach slope/topographic model is used to build up the three dimensional beach shape within the confines of the surrounding terrain and embankments. This is similar to the approach previously used by Fitton et al. (2008).

At this stage it is appropriate to consider what values could or should be used at the design phase to generate realistic distribution curves. 


\subsubsection{Feed rate}

Plant designs are typically carried out with using three throughput rates; a nominal design value, plus maximum and minimum values. Maximum values may be $10-15 \%$ above the nominal, and minimum values somewhat more (20-25\%) below. One possibility would therefore be to use these project specific values directly for calculation of the middle, lower and upper beach slopes respectively. In some cases this may result in a larger variation in parameters than those adopted for this study. Most plants try to avoid operating for long periods at low production rates, and consequently the spread across the full design throughput may be unrealistically high. However, as noted previously, the use of a value of 0.10 for coefficient of variation in this study appears to typically underestimate concavity, and higher variability may be justified.

Finally, it should be recognised that frequently as soon as a plant is commissioned there is a concerted effort to fine-tune the process to increase production to greater than the design throughput. A beach slope prediction based on the nominal and maximum design throughput may therefore prove to be slightly unconservative.

\subsubsection{Solids concentration}

Manufacturers' recommendations regarding thickener performance typically relate to expected maximum performance (underflow solids concentration), with little suggestion of possible variations. Even if the system performs to expectations, it is unlikely that there will be much variation on the high side of this prediction. This suggests that using the recommended maximum to predict the central part of the beach may be optimistic. It may be more reasonable to use this value for the upper limit of the cumulative distribution, or alternatively for the upper third of the beach slope.

In the absence of operational data on an equivalent thickener, it is suggested that a coefficient of variation in the range $0.03-0.06$ could be used (refer Table 2).

The Miduk case highlights the need to consider the possibility of slurry dilution between discharge from the thickener and deposition on the beach. This may need to include such sources as gland water if the slurry is pumped.

\section{Conclusions}

In cases where the input data for throughput, solids concentration and rheology are well defined, the beach slope model used in this paper (the Fitton non-segregating method) provides a reasonable prediction of measured beach slopes.

Beach slope concavity can be replicated by making allowance for the statistical variability of the key input parameters.

The method of analysis can be used for forward prediction of beach profiles and concavity.

Monitoring of thickened discharge schemes should require measurement and recording of key parameters (throughput and slurry concentration) on a daily or shift basis. Regular (annual) surveys of beach slope should be undertaken, and the rheology should be checked periodically.

\section{Acknowledgements}

The authors would like to thank the management and staff at the sites used in this study for the provision of the base data sets. Many of the technical staff at ATC Williams have been involved in the design and ongoing monitoring of a number of these facilities, and have contributed to the data collection required for this paper. We would particularly like to mention the contribution of Peter Lam, who undertook much of the rheological testing.

\section{References}

Amiconi, T. and Seddon, K.D. (1999) Design of an Integrated Water Management System for the Ernest Henry Mine, AMF, Biomine 99 and Water Management Conference, Perth, Australia. 
Fitton, T.G., Williams, M.P.A., Seddon, K.D., Bhattacharya, S.N. and Chryss, A.G. (2007) Simulation of Thickened Tailings Stacks, in Proceedings Tenth International Seminar on Paste and Thickened Tailings (Paste07), A.B. Fourie and R.J. Jewell (eds), 13-15 March 2007, Perth, Australia, Australian Centre for Geomechanics, Perth, pp. 305-314.

Fitton, T.G., Bhattacharya, S.N. and Chryss, A.G. (2008) Three-dimensional modelling of tailings beach shape, Computer-Aided Civil and Infrastructure Engineering, Vol. 23, pp. 31-44.

Jewell, R.J. (2010) Ensuring the credibility of thickening technology, in Proceedings 13th International Seminar on Paste and Thickened Tailings (Paste2010), R.J. Jewell and A.B. Fourie (eds), 3-6 May 2010, Toronto, Canada, Australian Centre for Geomechanics, Perth, pp. 23-32.

Murphy, S. (2006) Thickened tailings at Century Zinc Mine: A Case Study, Mine Tailings 2006, Brisbane, March 2006.

Pirouz, B. and Williams, M.P.A. (2007) Prediction of non-segregating thickened tailings beach slopes - a new method, in Proceedings Tenth International Seminar on Paste and Thickened Tailings (Paste07), A.B. Fourie and R.J. Jewell (eds), 13-15 March 2007, Perth, Australia, Australian Centre for Geomechanics, Perth, pp. 315-327.

Robinsky, E.I. (1999) Thickened Tailings Disposal in the Mining Industry, E.I. Robinsky Associates Limited, Toronto, Canada.

Williams, P. (2001) Tailings Beach Slope Forecasting: A Review, in Proceedings 4th International Seminar on Paste and Thickened Tailings, Pilanesberg, South Africa.

Williams, M.P.A., Murphy, S., MacNamara, L. and Khoshniaz, N. (2006) The Miduk Copper Project: Down-Valley Discharge of Paste Thickened Tailings, Design and Early Operating Experience, in Proceedings Ninth International Seminar on Paste and Thickened Tailings (Paste06), R.J. Jewell, S. Lawson and P. Newman (eds), 3-7 April 2006, Limerick, Ireland, Australian Centre for Geomechanics, Perth, pp. 117-130.

Williams, M.P.A., Seddon, K.D. and Fitton, T.G. (2008) Surface Disposal of Paste and Thickened Tailings - A Brief History and Current Confronting Issues, in Proceedings 11th International Seminar on Paste and Thickened Tailings (Paste08), A.B. Fourie, R.J. Jewell, P. Slatter and A. Paterson (eds), 5-9 May 2008, Kasane, Botswana, Australian Centre for Geomechanics, Perth, pp. 143-164. 
